\title{
FILLER DISPERSION IN HYPERBRANCHED POLYISOBUTYLENE
}

\author{
C. M. RoLAND* \\ Naval Research Laboratory, Code 6120, Washington DC 20375-5342 \\ C. G. ROBERTSON \\ Bridgestone/Firestone Research, InC.,1200 Firestone Parkway, AKron, OH 44317-0001 \\ L. NIKIEL \\ Sid Richardson Carbon Co., 4825 N. FreEway, Fort Worth, TX 76106 \\ J. E. PUSKAS \\ Department of Polymer Science, University of AKron, Akron, OH 44325-3909
}

\begin{abstract}
The microdispersion of carbon black filler in linear and hyperbranched polyisobutylene (PIB) was assessed from dynamic mechanical and volume resistivity measurements. While no significant differences were observed in the carbon black concentration necessary for formation of a filler network, in comparison to the linear polymer, the highly branched PIB was found to have substantially more carbon black agglomeration. This occurs despite its higher viscosity, due to the relative inaccessibility of large portions of the molecule, as a result of the profuse treelike branching. The consequence is more extensive interaggregate interaction, and thus a larger Payne effect and greater mechanical hysteresis.
\end{abstract}

\section{INTRODUCTION}

Branching is an attractive route to improving the processibility and physical properties of rubbers, since implementation may only require modification of existing synthetic methods. It is well known that even a single, long (i.e., well-entangled) branch per molecule can effect substantial changes in the melt rheology. ${ }^{1-6}$ Long chain branching alters both the shear-rate dependence $^{7-10}$ and the strain dependence ${ }^{11-13}$ of the rheological response, as well as enhancing strainhardening in extensional flow. ${ }^{14-17}$ On the other hand, a multiplicity of short branches can yield high molecular weight polymers having very low melt viscosities, ${ }^{18,19}$ albeit at the expense of some cured properties. ${ }^{20}$

Polyisobutylene (PIB) is one of the more interesting rubbers. The properties of the linear polymer have been studied by many techniques, including mechanical spectroscopy, ${ }^{21-24}$ light scattering, ${ }^{25}$ optical birefringence, ${ }^{26,27}$ neutron scattering, ${ }^{28,29}$ dielectric spectroscopy ${ }^{29}$ and computer simulation. ${ }^{30,31} \mathrm{~A}$ few studies of star-branched PIB have appeared, ${ }^{32,33}$ while our recent interest has been the viscoelastic response of hyperbranched polyisobutylene. ${ }^{34-36}$ Produced by carbocationic polymerization, these materials have a random, tree-like structure, ${ }^{37}$ lacking the self-similarity of dendrimers. Unlike common dendrimers and other hyperbranched polymers, the PIB have high molecular weight, entangled branches, although viscosity enhancement requires molecular weights well beyond the critical molecular weight for linear PIB $\left(\mathrm{M}_{\mathrm{c}}=\right.$ 15,200 daltons $^{38}$ ). Surprisingly, the viscosity of hyperbranched PIB is governed primarily by the number of branches, rather than their length, which is opposite from results for polymer stars. ${ }^{6}$ On the other hand, when compared at equal zero shear viscosity, the non-linear viscoelastic properties of linear and hyperbranched PIB are quite similar, except at very high shear rates. ${ }^{35}$

Utilization of rubber often relies on incorporation of reinforcing fillers, to improve processibility, as well as the physical properties of the cured elastomer. ${ }^{39}$ We previously noted ${ }^{35}$ that

* Corresponding author. Ph: 202-767-1719; Fax: 202-767-0594; email: roland@nrl.navy.mil 
when reinforced with carbon black, the dynamic modulus of hyperbranched PIB at low strain was large in comparison to linear PIB. A manifestation of the Payne effect, ${ }^{40}$ such behavior is consistent with more agglomeration of the filler in the former, suggesting that the core regions of highly branched molecules may be less accessible to the filler particles. Less interaction with polymer chains would promote interaction among the filler aggregates themselves. In this work, we test this hypothesis by comparing the low strain dynamic mechanical behavior and the electrical properties of linear and hyperbranched PIB. We do this as a function of carbon black content in the two polymers, to assess both the percolation point and the properties beyond the percolation threshold. The results reveal how the branching architecture can influence the dispersion of carbon black in the rubber.

\section{EXPERIMENTAL}

Hyperbranched PIB was synthesized by copolymerizing isobutylene with 4-(2-methoxyisopropyl)styrene, an "inimer" combining monomer and initiator functions. The structure is depicted in Figure 1. The hyperbranched sample had a weight average molecular weight, $M_{w}=790,000$ daltons, with a polydispersity of 1.3 . There were 44 branches per molecule (number-average), with $\mathrm{M}_{\mathrm{w}}$ for the branches equal to 17,900 D. The linear PIB (Aldrich 9003-27-4) had a $\mathrm{M}_{\mathrm{w}}=$ $389,000 \mathrm{D}$, and a polydispersity of 2.5 . Linear viscoelastic properties of neat polymers with very similar architectures were reported elsewhere. ${ }^{34}$ The zero-shear viscosity of the gums (i.e., unfilled rubbers) at $25 \mathrm{C}$ is $1.3 \times 10^{8}$ and $1.8 \times 10^{9} \mathrm{~Pa} \mathrm{~s}$, for the linear and hyperbranched samples, respectively. ${ }^{34}$ For the present study, 10 to $60 \mathrm{phr}$ of N234 carbon black ("ISAF-HS", a high structure, fine particle black) were solution blended into the rubber. After drying, the compounds were mixed extensively on a two-roll mill - forty passes at increasing speeds up to $16 \mathrm{~cm} / \mathrm{s}$, which, for $7.6 \mathrm{~cm}$ diameter rolls and a $0.1 \mathrm{~mm}$ nip setting, corresponds (assuming no slippage) to a nominal shear rate exceeding $10^{4} \mathrm{rad} / \mathrm{s} .{ }^{41}$ Subsequent to mixing, the carbon black macrodispersion was assessed using a Federal Products Surfanalyzer 2000. This profilometer measures the topography of a cut surface, which is cross-referenced to optical microscopy results. Measurements were obtained on two cut surfaces each for samples of the linear and hyperbranched PIBs with carbon black content of 20, 30, 40, and $60 \mathrm{phr}$.

Dynamic shear measurements were conducted in torsion at $25{ }^{\circ} \mathrm{C}$ using a Rheometrics ARES mechanical spectrometer. Samples were in the form of disks (18.5 $\mathrm{mm}$ in diameter and $2.7 \pm 0.8 \mathrm{~mm}$ thick), with $11 \mathrm{~mm}$ diameter holes cut from the center. The latter minimizes the distribution of strain amplitudes when using a parallel plate geometry. The plates were serrated to avoid slippage. Measurements were carried out at a fixed frequency of $10 \mathrm{rad} / \mathrm{s}$, varying the strain from $0.01 \%$ to as large as $40 \%$ (as governed by the maximum torque of $2000 \mathrm{~g}-\mathrm{cm}$ ). The moduli reported herein were corrected to account for the ring geometry.

For electrical conductivity measurements, similar-sized disks, without center holes, were molded, and the faces coated with conducting silver paint. Volume resistivities were obtained using the alternating polarity method. ${ }^{42}$ The current was repeatedly measured (Keithley Instruments 6517A electrometer) after application of DC voltages of alternating polarity. The use of a reversing polarity circumvents problems with residual charges and decaying background currents. A guard ring was in contact with the sample to deplete surface currents. 


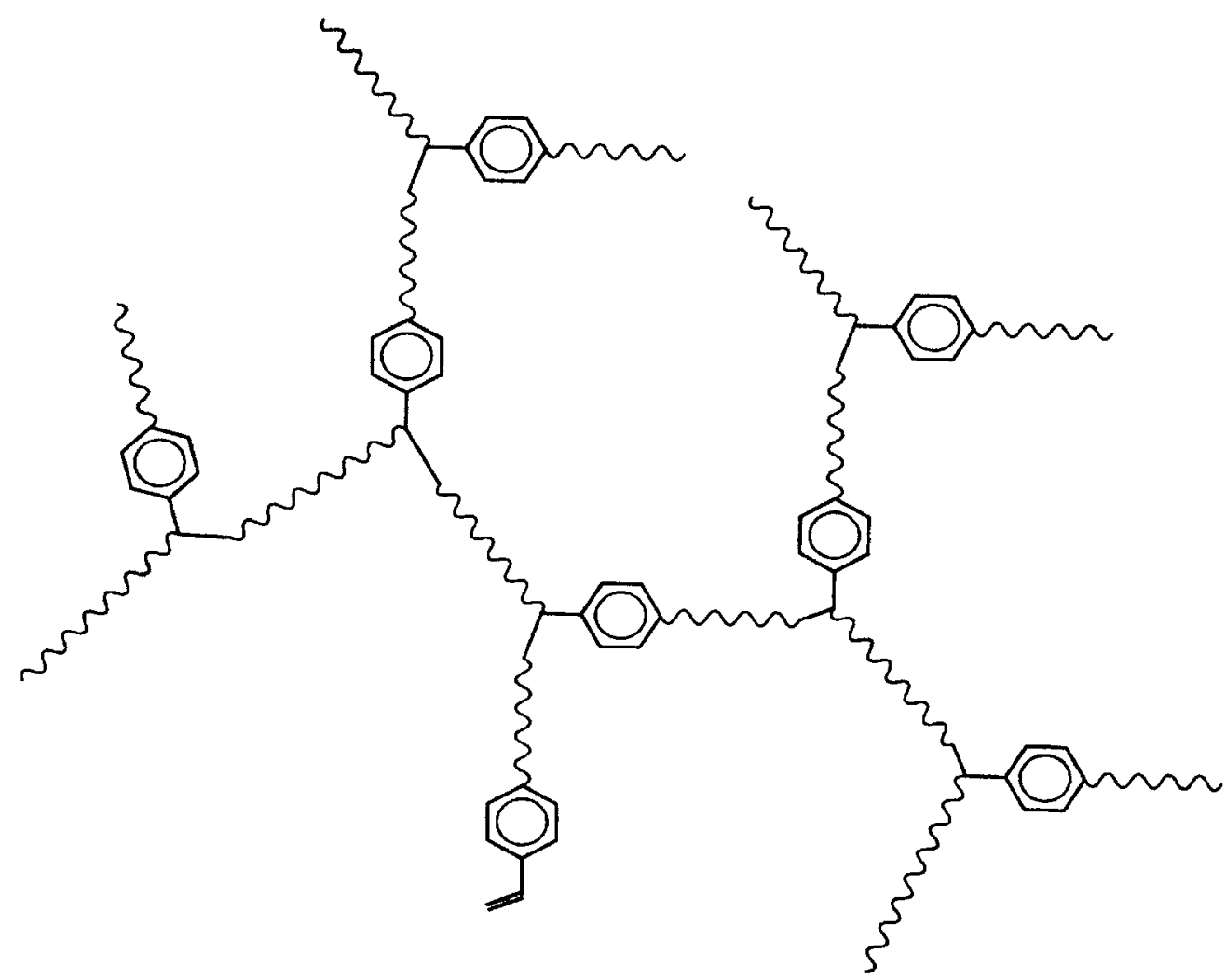

FIG. 1. - Representative structure of hyperbranched polyisobutylene. The polymer studied herein had a functionality of 3 , with 44 branches (both interior and dangling) per molecule.

\section{RESULTS}

Mixing of all compounds was carried out in an identical fashion, intended to give uniform distribution and good macrodispersion of the carbon black. The latter was affirmed by carbon black dispersion ratings, equal to $96 \pm 2 \%$, with no difference between the two polyisobutylenes. This dispersion number refers to the percentage of aggregate particles smaller than $5 \mu \mathrm{m}$. A measure of the fine-scale dispersion of the carbon black can be gleaned from the strain amplitude dependence of the dynamic modulus. Poorer dispersion yields higher modulus for strains insufficient to disrupt the carbon black agglomerates. ${ }^{40}$ Figure 2 shows the strain dependence of the dynamic storage, $G^{\prime}$, and loss, $G$ ", moduli for the linear and hyperbranched PIB having 60 phr carbon black. At this loading, there is a well-developed filler network, and thus the modulus is high at low strain. The magnitude of the plateau in $G^{\prime}$, which extends to infinitely low deformation, ${ }^{43-45}$ reflects amplification of the rubber modulus due to the flocculated carbon black. However, the data in Figure 2 are not directly informative, since the branched PIB has a larger viscosity in the absence of filler. A more accurate measure of the extent of filler network formation is the magnitude of the loss peak, as well as the change in $G^{\prime}$ with strain, both of which reflect breakup of the filler agglomerates. These are also greater for the branched sample, indicating the presence of a more extensive network of the carbon black. Disruption of the filler network at higher strains ( $\mathrm{ca} .1 \%)$ brings the dynamic response of the two materials closer together. 


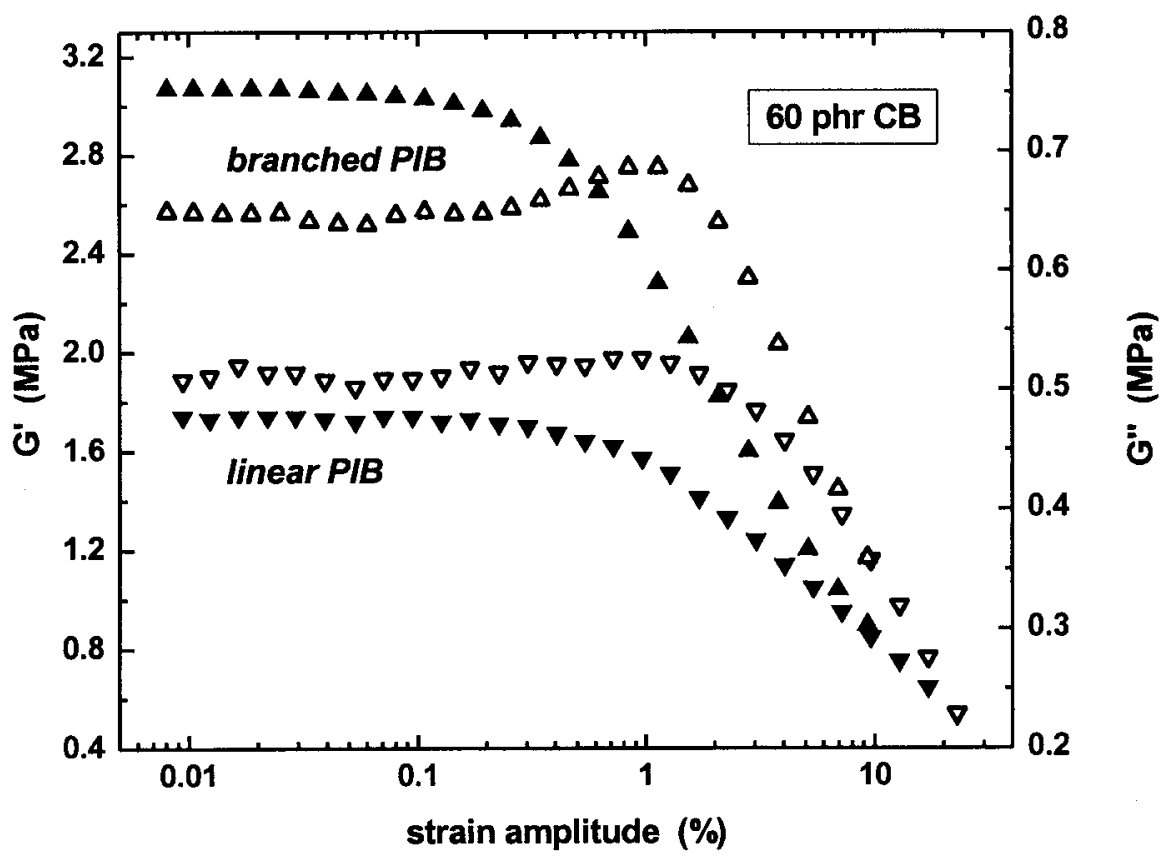

FIG. 2. - Storage (solid symbols) and loss (hollow symbols) moduli for the linear and hyperbranched PIB.

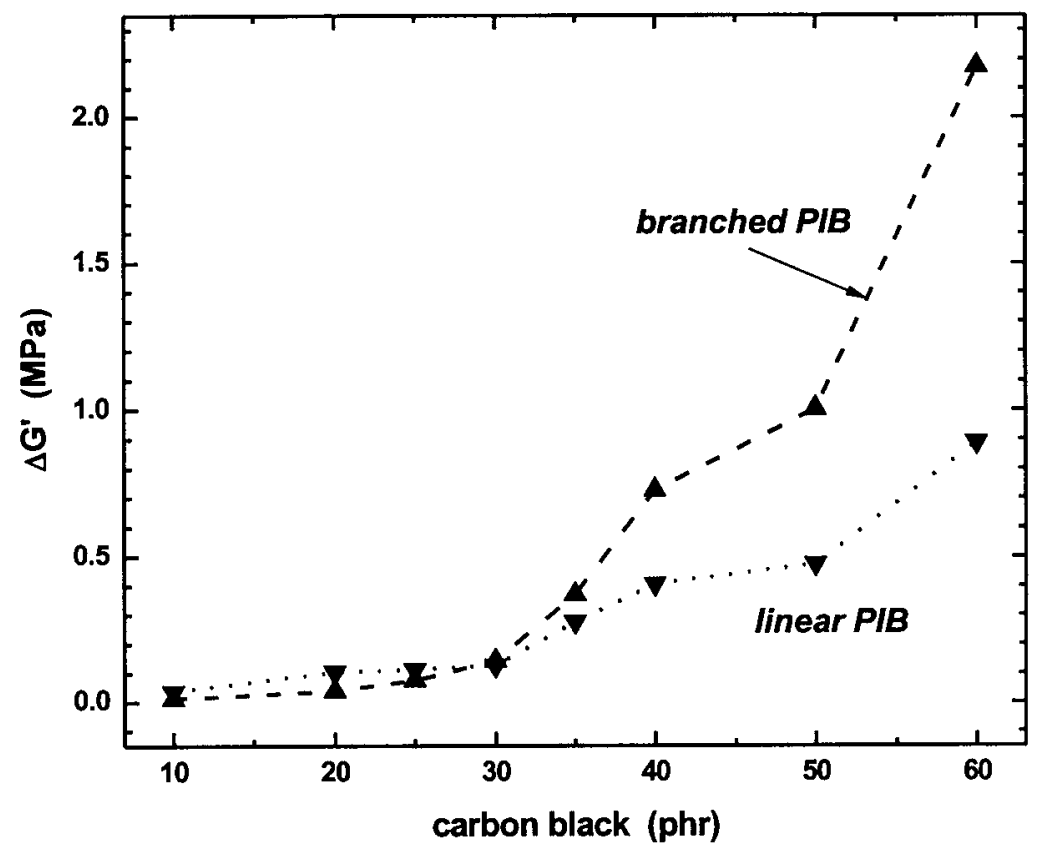

FIG. 3. - Difference in the storage modulus measured at strain amplitude equal to $0.01 \%$ and $10 \%$ for the linear $(\boldsymbol{\nabla})$ and hyperbranched $(\boldsymbol{\Delta})$ PIB.

In Figure 3, the difference between the storage modulus for low $(0.01 \%)$ and high $(10 \%)$ strain, $\Delta \mathrm{G}^{\prime}$, is plotted as a function of carbon black content. At low filler concentration, (below about $30 \mathrm{phr}$ ), the change in storage modulus with strain is essentially the same for the two poly- 
mers. At higher levels of carbon black, there is a change in the behavior, with the strain-dependence of the modulus increasing markedly. This denotes the onset of a three-dimensional network (percolation) of the aggregates. While no clear difference in the percolation point for the two samples is evident, there is a stronger increase in modulus with strain for the hyperbranched PIB. The difference in $\Delta \mathrm{G}^{\prime}$ is largest at $60 \mathrm{phr}$ of the N234 (see Figure 3).

A more agglomerated filler yields greater hysteresis when subjected to strains sufficient to effect de-flocculation. This is because debonding of the filler particles is reversible, with the network reforming during each strain cycle. This process converts mechanical energy to heat; accordingly, the loss modulus, associated with breakup of the network, increases with strain amplitude. The increase is most evident for carbon black concentrations beyond the percolation point. This behavior is seen in Figure 4, showing the maximum in the loss modulus for each sample. Note that beyond $30 \mathrm{phr}$ of filler, the peak in $G$ ” is greater for the hyperbranched PIB, in comparison to its linear counterpart. This result is in accord with the data in Figure 3.

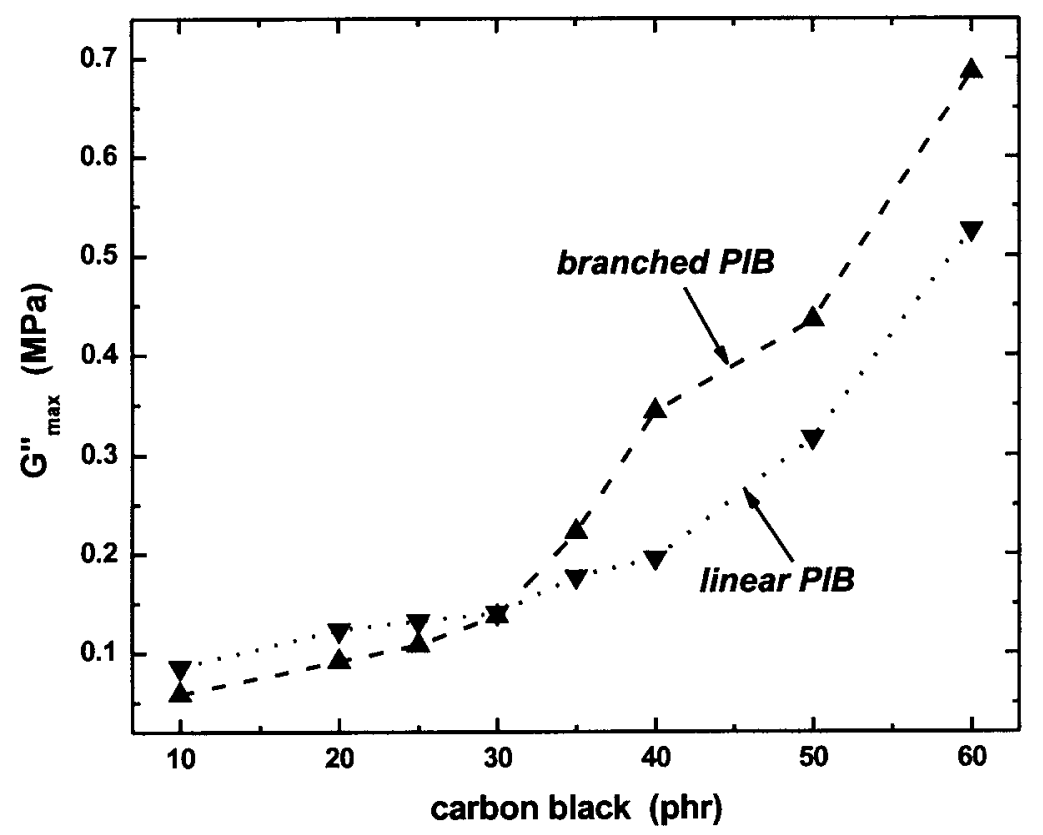

FIG. 4. - The maximum in the loss modulus for the linear $(\boldsymbol{\nabla})$ and hyperbranched $(\mathbf{\Delta})$ PIB.

We also expect that increased agglomeration will affect the electrical conductivity. Displayed in Figure 5 is the volume resistivity measured for all samples. At sufficient filler content, a conductive network is formed. ${ }^{42,46,47}$ This gives rise to a change in slope of the resistivity versus concentration curve in the vicinity of $30 \mathrm{phr}$ carbon black. This is consistent with the mechanical data in Figures 3 and 4. Although the precision of the resistivity data is poor (and inherent to such measurements ${ }^{48}$ ), differences for the two polymers are evident. The hyperbranched PIB appears to have a higher percolation point, which usually indicates better dispersion. However, the well-formed networks at higher filler concentrations yield lower volume resistivity in the branched PIB. This clearly indicates more interaggregate contacts, consistent with the mechanical data. The crossover behavior in Figure 5 is unusual. The data at very low loading may reflect poorly dispersed, flocculated carbon black in the branched polymer, resulting in high resistivity and a higher percolation threshold. At higher concentrations of filler, the number of electrical connections increases, leading to lower resistivity than for the linear PIB. 


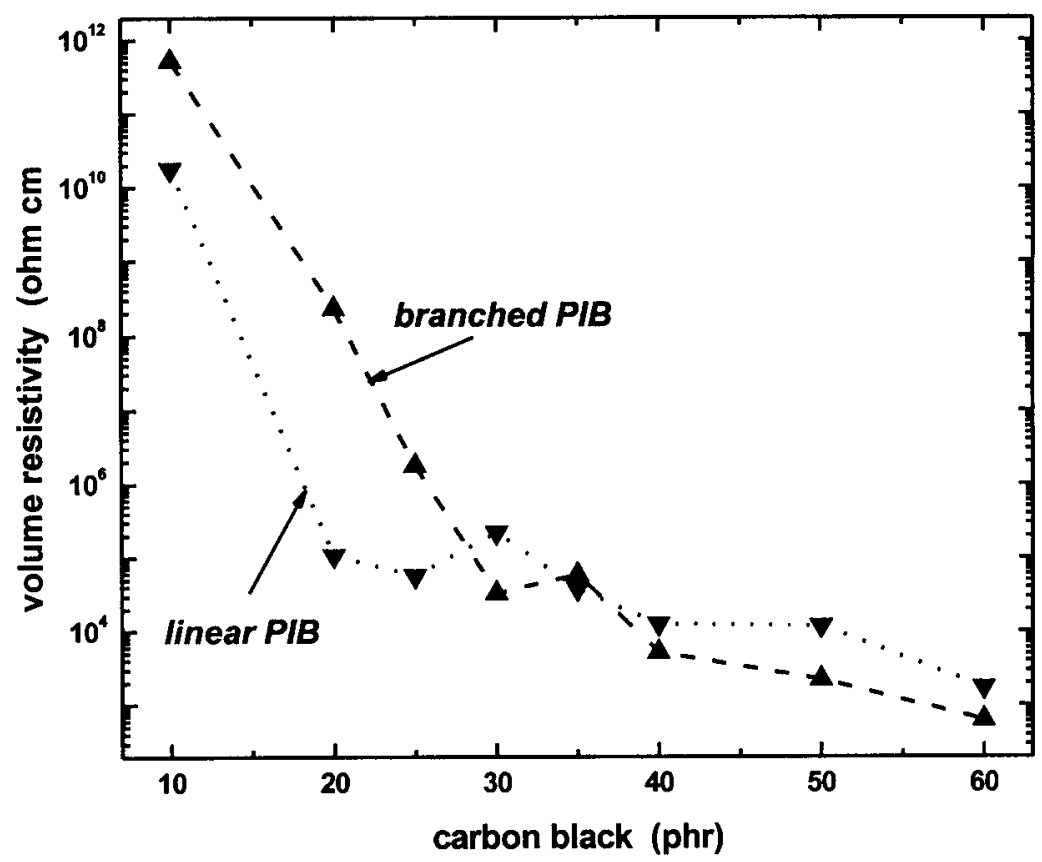

FIG. 5. - DC volume resistivity measured by the alternating polarity method for the linear $(\boldsymbol{\nabla})$ and hyperbranched $(\mathbf{\Delta})$ PIB.

\section{SUMMARY}

Both the mechanical and electrical data confirm that carbon black agglomeration is more extensive in the hyperbranched PIB. This implies that poorer dispersion of the filler is attained during mixing of carbon black into the hyperbranched PIB, than is the case for the linear polymer. Note that the latter has a lower viscosity, which means that at equal mixing temperatures, stresses will be smaller for the linear PIB. Smaller mixing stresses lead to the expectation of worse filler dispersion, contrary to the experimental results. (This effect of viscosity on mixing behavior is also seen in star-branched polymers. ${ }^{49}$ ) Why is filler dispersion inherently more difficult with the hyperbranched polymer?

Figure 1 illustrates the structure of a portion of a hyperbranched molecule. The material used herein had 44 branches per molecule, so that the structure in Figure 1 extends about six-fold further. Clearly, there is an extensive volume of the interior of the molecule that is excluded, by steric constraints, from intimate contact with the carbon black particle. The interaction of the saturated PIB chains with the filler surface is physical adsorption through formation of van der Waals bonds. The strength of a van der Waals bond is strongly distance dependence $\left(\sim \mathrm{r}^{-6}\right)$, but a multi-tiered structure may preclude interior chain segments from gaining close proximity to the filler particles. Note that high branching densities are known to reduce intermolecular penetration in star polymers ${ }^{50,51}$ and dendrimers. ${ }^{53}$ The large inaccessible volume of the hyperbranched PIB structure leaves more filler surface area available for bonding with other filler particles. The result is formation of a more extensive interaggregate network. Although the consequently poorer mechanical efficiency and greater heat buildup of the elastomer are often undesirable, there are applications, such as conductive rubber, in which this effect of branching on the dispersion process might be exploited. 


\section{ACKNOWLEDGEMENTS}

The work at NRL was supported by the Office of Naval Research. CGR thanks Bridgestone/Firestone Research and LN the Sid Richardson Carbon Company for permission to publish this work.

\section{REFERENCES}

${ }^{1}$ M. Doi, "Structure and Properties of Polymers," E.L. Thomas, ed., Wiley-VCH: Weinheim, 1993, ch. 9.

${ }^{2}$ C. M. Roland and C. A. Bero, Macromolecules 29, 7521 (1996).

${ }^{3}$ C. A. Bero and C. M. Roland, Macromolecules 29, 1562 (1996).

${ }^{4}$ P. G. Santangelo and C. M. Roland, J. Non-Crystalline Solids 235, 709 (1998).

${ }^{5}$ J. M. Carella, J. T. Gotro, and W. W. Graessley, Macromolecules 19, 659 (1986).

${ }^{6}$ G. S. Grest, L. J. Fetters, J. S. Huang, and D. Richter Adv. Chem. Phys. 94, 67 (1996).

${ }^{7}$ W. W. Graessley, Acct. of Chem. Res. 10, 332 (1977).

${ }^{8}$ L. J. Fetters, A. D. Kiss, D. S. Pearson, G. F. Quack, and F. J. Vitus, Macromolecules 26, 647 (1993).

${ }^{9}$ Y. S. Kim, C. I. Chung, S. Y. Lai, and K. S. Hyun, J. Appl. Polym. Sci. 59, 125 (1996).

${ }^{10}$ P. M. Wood-Adams, J. Rheol. 45, 203 (2001).

${ }^{11} \mathrm{~K}$. Osaki and M. Kurata, Macromolecules 13, 671 (1980).

${ }^{12}$ D. K. Bick T. C. B. McLeish, Phys. Rev. Letts. 76, 2587 (1996).

${ }^{13}$ L. J. Kasehagen and C. W. Macosko, J. Rheol. 42, 1303 (1998).

${ }^{14}$ J. Meissner, Pure Appl. Chem. 42, 553 (1975).

${ }^{15}$ D. S. Pearson, S. J. Mueller, L. J. Fetters, and N. Hadjichristidis, J. Polym. Sci. Polym. Phys. Ed. 21,2287 (1983).

${ }^{16}$ R. Hingmann and B. L. Marczinke, J. Rheol. 38, 573 (1994).

${ }^{17}$ N. J. Inkson, T. C. B. McLeish, O. G. Harlen, and D. J. Groves, J. Rheol. 43, 873 (1999).

${ }^{18}$ H. Claesson, E. Malmstrom, M. Johansson, and A. Hult, Polymer 43, 3511 (2002).

${ }^{19}$ B. D. M. A. Suneel, D.J. Groves, T. C. B. McLeish, D. Parker, A. J. Keeney, and W. J. Feast, Macromolecules 35, 9605 (2002).

${ }^{20}$ P. J. Flory, J. Amer. Chem. Soc. 69, 2893 (1947).

${ }^{21}$ E. R. Fitzgerald, L. D. Grandine, and J. D. Ferry, Phys. Rev. 91, 217 (1953).

${ }^{22}$ L. J. Fetters, W. W. Graessley and A. D. Kiss, Macromolecules 24, 3136 (1991).

${ }^{23}$ D.J. Plazek, I.-C. Chay, K.L. Ngai, and C.M. Roland, Macromolecules 28, 6432 (1995).

${ }^{24}$ P. G. Santangelo, K. L. Ngai, and C. M. Roland, Macromolecules 26, 2682 (1993).

${ }^{25}$ A. K. Rizos, T.Jian and K. L. Ngai, Macromolecules 28, 517 (1995).

${ }^{26}$ P. H. Mott, A. Rizos, and C. M. Roland, Macromolecules 34, 4476 (2001).

${ }^{27}$ H. Okamoto, T. Inoue, and K. Osaki J. Polym. Sci. Polym. Phys. Ed. 33, 1409 (1995).

${ }^{28}$ A. Triolo, R. E. Lechner, A. Desmedt, M. T. F. Telling, and V. Arrighi, Macromolecules 35, 7039 (2002).

${ }^{29}$ D. Richter, A. Arbe, J. Colmenero, M. Monkenbusch, B. Farago, and R. Faust Macromolecules 31, 1133 (1998).

${ }^{30}$ R. H. Boyd and P. V. K. Pant, Macromolecules 24, 6325 (1991).

${ }^{31}$ K. Karatasos, J.-P. Ryckaert, Macromolecules 34, 7232 (2001).

${ }^{32}$ S. Keki, G. Deak, A. Kuki and M. Zsuga, Polymer 39, 6053 (1988).

${ }^{33}$ P. G. Santangelo, C. M. Roland and J. E. Puskas, Macromolecules 32, 1972, (1999).

${ }^{34}$ C. G. Robertson, C. M. Roland, C. Paulo, and J. E. Puskas, J. Rheology, 45, 759 (2001).

${ }^{35}$ C. G. Robertson, C. M. Roland, and J. E. Puskas, J. Rheology 46, 307 (2002).

${ }^{36}$ J. E. Puskas, C. Paulo and V. Alstadt, Rubber Chem. Technol. 75, 853 (2002).

${ }^{37}$ C. Paulo and J. E. Puskas, Macromolecules 34, 734 (2001).

${ }^{38}$ W. W. Graessley and S. F. Edwards, Polymer 22, 1329 (1981). 
${ }^{39}$ A. I. Medalia and G. Kraus, in "Science and Technology of Rubber," $2^{\text {nd }}$ Edition, J.E. Mark, B. Erman, and F.R. Eirich, Eds., Academic Press, New York, 1994, ch. 8.

${ }^{40}$ A. R. Payne, J. Appl. Polym. Sci. 6, 57 (1962); 7, 873 (1963); 8, 2661 (1964).

${ }^{41}$ J. M. McKelvy, Polymer Processing, Wiley, New York, 1962, ch. 9.

${ }^{42}$ L. Nikiel, M. Gerspahcer, H. Yang, and C. P. O’Farrell, Rubber Chem. Technol. 74, 249 (2001).

${ }^{43}$ C.M. Roland and G.F. Lee, Rubber Chem. Technol. 63, 554 (1990).

${ }^{44}$ C.M. Roland, J. Rheol., 34, 25 (1990).

${ }^{45}$ M. Gerspacher, C. P. O’Farrell, L. Nikiel and H. H. Yang, Rubber Chem. Technol. 69, 786 (1996).

${ }^{46}$ B.B. Boonstra, Rubber Chem. TeChnOL. 50, 194 (1977).

${ }^{47}$ D.R. Fernandez and A.J. Marzocca, Rubber Chem. Technol. 64, 501 (1991).

${ }^{48}$ See, for example, J.R. Payne Eur. Rub. J., November 1981, p. 17.

${ }^{49}$ C. G. Robertson, C. M. Rademacher, T. E. Hogan, and G.G.A. Böhm, to be published.

${ }^{50}$ T. Pakula, D. Vlassopoulos, G. Fytas, and J. Roovers, Macromolecules 31, 8931 (1998).

${ }^{51}$ S.-Y. Kwak and H.Y. Lee, Macromolecules 33, 5536 (2000).

${ }^{52}$ P. J. Farrington, C. J. Hawker, J. M. J. Frichet, and M. E. Mackay, Macromolecules 31, 5043 (1998).

[ Received September 2003, revised February 2004] 